\title{
Una imagen del Tercer Encuentro de Conservación del Patrimonio Fotográfico, noviembre del 2010. MUAC-UNAM
}

\author{
Liliana Dávila Lorenzana \\ Ma. Estíbaliz Guzmán Solano \\ Claudio Hernández Hernández
}

\section{Introducción}

n julio del 2010, el Grupo de Conservadores de Fotografías (GCF) difundió por medios electrónicos la convocatoria para la participación de un gran acontecimiento multinacional: el Tercer Encuentro de Conservación del Patrimonio Fotográfico (TECPF). Su objetivo principal era favorecer el intercambio y la actualización del gremio en torno de la conservación de fotografías, junto con aquellos bienes culturales que la acompañan y constituyen como un medio de expresión cultural que, en gran medida, ha modelado la experiencia estética, documental e histórica de los últimos tres siglos.

El encuentro tuvo lugar el 4 de noviembre de 2010 en el auditorio del Museo Universitario Arte Contemporáneo (MUAC-UNAM), en Ciudad Universitaria, México. Se presentaron once ponencias de México y España enfocadas a diferentes tendencias de desarrollo de la conservación de patrimonio fotográfico. Dada la importancia del encuentro, esta reseña busca reflexionar sobre sus contribuciones desde una postura crítica.

\section{Un balance}

Uno de los aciertos más significativos del TECPF fue su organización mediante mesas enfocadas en temas de gran importancia y actualidad en el campo de la conservación-restauración en general y de la preservación del legado fotográfico en particular. Así, las contribuciones se dividieron en cuatro rubros:

- "Gestión y conservación de colecciones", que abordó las metodologías de trabajo instrumentadas por diversas instituciones para el estudio y la conservación de colecciones fotográficas.

- "Acervos frente a la era digital", dedicado a reflexionar sobre las ventajas y desventajas de las imágenes digitales en el aspecto de su almacenamiento. 
"La restauración de objetos fotográficos", donde puntualmente se relataron resultados obtenidos en la aplicación de procesos de restauración en materiales específicos.

"Teoría-casos de estudio", que acentuó la importancia de las imágenes para la comprensión, la profundización, el estudio y la caracterización de distintos momentos históricos y estilísticos.

Esta división temática permitió no sólo que el GCF refrendara, con una perspectiva amplia y diversificada, su compromiso con la conservación de materiales fotográficos y que se contara con la participación de ponentes y asistentes nacionales e internacionales involucrados en distintos ámbitos de competencia de la conservación, la preservación, el estudio y el manejo del campo, sino también que se propiciara una discusión centrada y organizada que dio valor tanto a las experiencias, inquietudes o reflexiones acerca de la conservación y restauración como a la difusión de nuevas investigaciones, cursos y talleres.

\section{Conclusiones}

La rica y variada gama de experiencias de especialistas expuesta en el TECPF facilitó que se arribara a conclusiones específicas sobre los principales temas de cuatro ámbitos particulares: el examen de materiales y técnicas fotográficas; la valoración y el significado de objetos y colecciones; la preservación, la conservación y los tratamientos de restauración, así como, por último, la difusión.

Se determinó que es fundamental identificar la materialidad de los componentes del patrimonio fotográfico, con especial énfasis en la relación con la historia tecnológica de la fotografía y con las características fisicoquímicas de los propios bienes culturales. Esta perspectiva integrada no sólo favorecerá avances en el conocimiento e investigación

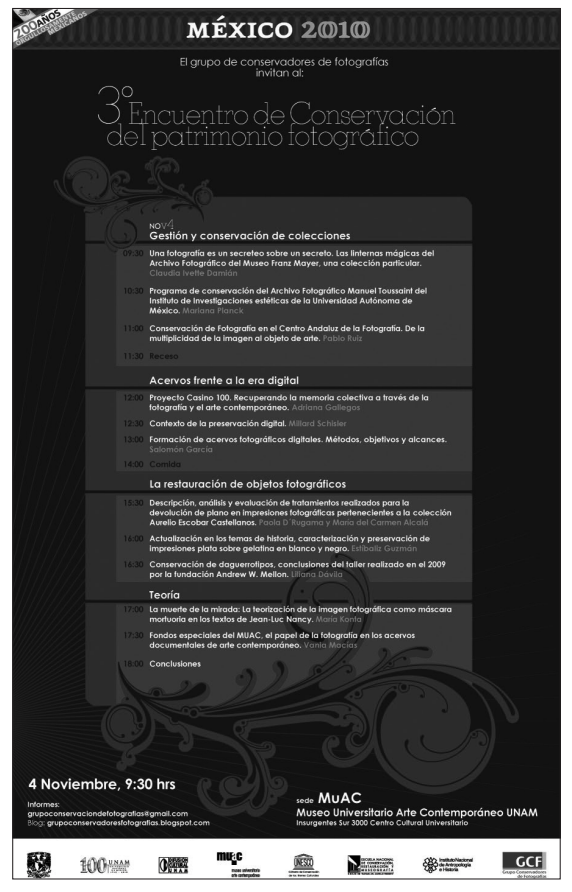

FIGURA 1. Cartel de difusión del Tercer Encuentro de Conservación del Patrimonio Fotográfico. (Cortesía del GCF).

del legado histórico fotográfico, sino que servirá de base para la toma de decisiones centradas en favorecer su estabilidad y preservación a futuro.

Resulta fundamental -se resaltóla creación de bases de datos a partir de información presentada en seminarios periódicos, con el fin de compartir la obtenida por instituciones educativas, museos, archivos y especialistas privados involucrados con colecciones fotográficas. También se remarcó la necesidad de documentar y difundir las nuevas investigaciones sobre la tecnología de procesos fotográficos, una fuente de conocimiento resultante del acercamiento real que como conservadores, archivistas y otros especialistas tenemos con su materialidad.

Asimismo, se concluyó que determinar claramente la valoración y el significado de las fotografías no sólo es sustancial, sino un proceso básico para acercarse a la obra. La relevancia histórica, tecnológica, científica y social de materiales fotográficos -aspectos evaluados en distintas ponencias durante el encuentro- permite precisar su importancia actual y pro- yectar su conservación a futuro de manera coherente, informada y sistemática. Un aspecto digno de mencionar es que durante el encuentro se enfatizó la trascendencia de conocer la multiplicidad de interpretaciones que la fotografía guarda como objeto, con el fin de que su conservación sea coherente con los públicos o agentes que le asignan relevancia en la actualidad.

El TECPF fue sumamente enriquecedor en cuanto a la actualización en temas de preservación, conservación y restauración de patrimonio fotográfico, ya que además de discutir diferentes experiencias relativas a estos ámbitos, se analizó la relación de estas iniciativas con plataformas de gestión, visiones y misiones institucionales, recursos económicos y tipo de colecciones. Se expusieron diferentes propuestas ideales y ejecutables a través de acciones prácticas, creíbles y eficientes tanto a corto como a mediano plazos. Una consideración fundamental fue que, para realizar restauraciones óptimas, se requiere la actualización especializada en la evaluación de diferentes tratamientos, reflexión que nos lleva al tema de la difusión.

Efectivamente, durante el foro se insistió en los beneficios de contar con un acervo de experiencia en restauración, el cual ha servido como referencia suficiente para comparar resultados de investigaciones e intervenciones de los últimos 30 años. Tomando en cuenta lo anterior, el TECPF concluyó que, aunque vivimos en un mundo sumergido en la tecnología digital, todavía existen deficiencias en la terminología y el método empleado en la preservación, tanto de obra de exposición como de material de archivo. De ahí que sea necesario hacer un esfuerzo compartido en la edición de publicaciones dedicadas a difundir las experiencias actuales con la fotografía digital -ya sea de origen o de conversión-, así como de prototipos de manuales donde el usuario encuentre información relevante sobre cada uno de los pasos esenciales que se han de seguir 
para la conservación de materiales fotográficos tanto analógicos como digitales.

En cumplimiento con este compromiso, el GFC está en busca de publicar las memorias sobre pasados encuentros y actividades académicas o de formación, organizadas bajo su competencia (<grupoconservadoresfotografias.blogspot.com>, <grupoconservaciondefotografias@gmail. com>). Se ha anunciado la edición de las memorias del TECPF, que prometen ser un documento de referencia para el desarrollo de la conservación de patrimonio fotográfico y que, esperamos, no sólo despierte interés, sino iniciativas para su pronta reseña.

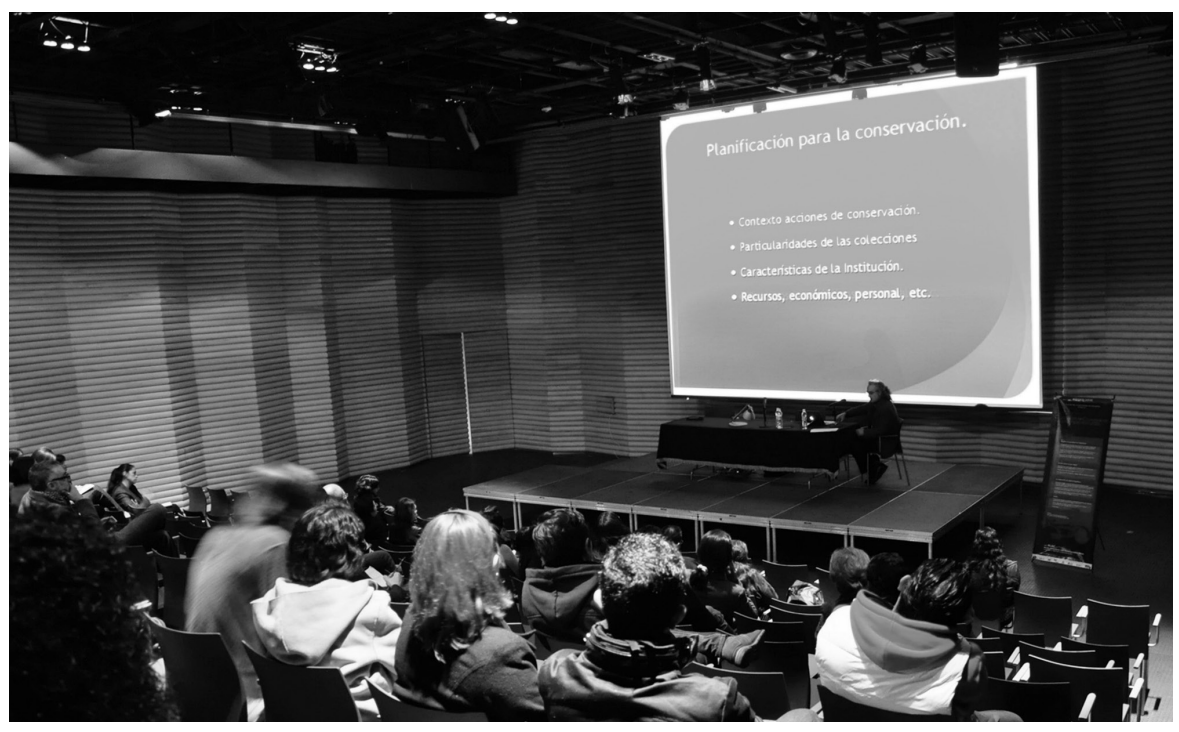

Figura 2. Imagen del Tercer Encuentro de Conservación del Patrimonio Fotográfico. (Cortesía del GCF).

\section{Resumen}

En esta reseña se analizan las actividades y contribuciones del Tercer Encuentro de Conservación del Patrimonio Fotográfico organizado por el Grupo de Conservadores de Fotografías (GCF), el cual tuvo lugar el 4 de noviembre de 2010 en el Museo Universitario Arte Contemporáneo (MUAC), UNAM, Ciudad de México. Dividido en cuatro mesas temáticas centrales sobre la gestión y conservación de colecciones, acervos y objetos fotográficos, este foro constituyó la reunión de expertos más relevante de los últimos años en torno al patrimonio fotográfico en América Latina, razón por la cual sus conclusiones perfilan como modeladores del futuro de este joven campo de desarrollo profesional.

\section{Palabras clave}

Fotografía, encuentro, conservación, restauración.

\section{Abstract}

On November 4th of last year, the Grupo de Conservadores de Fotografías (GCF) organized the Third Annual Meeting of Photograph Conservation hosted at the Museo Universitario Arte Contemporáneo (MUAC) in Mexico City. Papers highlighted the management and conservation of collections, archives and photographic materials. To date, this meeting constituted the most important event in Latin America, therefore, its conclusions are fundamental for the development of this young field in our country.

\section{Keywords}

Photographs, Meeting, Conservation, Restoration. 